\title{
LA REFORMA CONSTITUCIONAL PENDIENTE EN MATERIA DE DERECHOS DE NIÑOS, NIÑAS Y ADOLESCENTES
}

\section{Mónica GONZÁLEZ CONTRÓ}

RESUMEN: El artículo pretende justificar la necesidad de una reforma constitucional en materia de derechos de niños, niñas y adolescentes que se ajuste a los lineamientos establecidos en los instrumentos internacionales y a la doctrina específica de esta rama del derecho. A través de una breve descripción de los antecedentes del tratamiento jurídico hacia la infancia y adolescencia, tanto en la Constitución mexicana como en el derecho internacional, se argumenta a favor de la creación de un nuevo marco jurídico para niños, niñas y adolescentes. Finalmente, se exponen los elementos básicos que debería recoger la reforma constitucional para garantizar la vigencia plena del Estado constitucional de derecho durante los primeros años de vida del ser humano.

Palabras clave: Niño, niña, adolescente, derechos fundamentales, principios, interés superior del niño, autonomía progresiva.
ABSTRACT: This article pretends to justify why a constitutional reform is needed in the subject of children's and adolescent's rights, a constitutional reform that fits to international instruments, and to the specific theory of this branch of law. Through a brief description of the antecedents of juridical treatment towards infancy and adolescence in the Mexican Constitution, and in international law, it is argumented in favor of the creation of a new lawful frame for children and adolescents. Finally, in order to guarantee the full validity of the Constitutional State for human beings during their first years of life, it is given the basic elements that this constitutional reform should contain.

Descriptors: Children, adolescents, fundamental rights, principles, best interest of the child, progressive autonomy. 


\section{INTRODUCCCIÓN}

La inclusión de los niños como titulares de derechos subjetivos, especialmente de las libertades reconocidas constitucionalmente, no ha sido sencillo. Ello se debe, en buena medida, a que la tradición liberal vincula especialmente a los derechos humanos con la autonomía de la persona. Efectivamente, en el surgimiento mismo de la idea moderna de los derechos del individuo frente al Estado es posible identificar la importancia que se concede a su autodeterminación frente al poder. Es precisamente esta idea la que da origen a la concepción de la Constitución como límite a la actuación pública, en el entendido de que hay espacios de la vida de los individuos en los que la autoridad tiene proscrito intervenir. En este proceso, las primeras declaraciones de derechos (en particular la francesa y la norteamericana) excluyen a quienes se consideraba carecían de esta capacidad de autonomía, es decir, a todo aquel que no fuera varón, adulto propietario y en este sentido ciudadano. A esta noción restringida del grupo destinatario de la titularidad de los derechos subjetivos públicos sobreviene posteriormente un proceso de generalización, en el cual la titularidad se va extendiendo hasta llegar a la idea de la universalidad de los llamados derechos humanos. Así lo reflejan las Constituciones modernas, la mayoría de las cuales contienen una cláusula de igualdad mediante la cual se entiende que la aplicación de los derechos contenidos en las mismas se garantizan en el territorio de aplicación a todas las personas por igual, aunque distinguiendo generalmente los derechos vinculados con la ciudadanía (por ejemplo los derechos de participación política) como exclusivos de los nacionales mayores de edad del Estado en cuestión.

En el proceso de surgimiento de los derechos, los niños (menores de edad) no sólo quedaron excluidos de la titularidad de derechos, sino que la misma concepción de los derechos subjetivos los consideró parte de la esfera de inmunidad que correspondía al varón-adulto-propietario. Esto significa que una de las libertades frente al Estado consistía precisamente en la no interferencia pública en el espacio privado de la familia. Así, los hombres y mujeres durante la infancia prácticamente "pertenecían" al padre, quien tenía como prerrogativa la libertad para educarlos y tratarlos de la forma en que creyera más adecuada. En Francia, durante el siglo XIX, este poder comprendía incluso la facultad del padre para hacer uso 
de las prisiones del Estado en el caso tener "motivos muy graves de queja por la conducta de un hijo":

El padre puede hacer detener a sus hijos y echar mano de las prisiones del Estado..."El padre que tiene motivos muy graves de queja por la conducta de un hijo" puede apelar ante el tribunal de distrito; hasta los 16 años, la detención no puede exceder de un mes; desde esa edad hasta la mayoría, puede alcanzar hasta los seis meses. Las formalidades $-\mathrm{y}$ las garantías - son muy reducidas: no hay ningún documento escrito ni ninguna formalidad judicial, como no sea la orden misma de arresto, en la que no aparecen enunciados los motivos. Si tras su libertad, el hijo "cae en nuevos extravíos", puede ordenarse de nuevo su detención. ${ }^{1}$

Esta situación no cambió significativamente hasta el sigo XX, en el que comienza a darse una incipiente concepción sobre los derechos de los niños.

\section{LA EVOLUCIÓN DE LOS DERECHOS DE LOS NIÑOS EN EL DERECHO INTERNACIONAL}

El primer instrumento sobre derechos del niño en el ámbito internacional es la Declaración de Ginebra, que tiene su origen en la iniciativa de la británica Eglantyne Jebb, fundadora de la organización Save de Children, cuyo objetivo era ayudar a los niños víctimas de la primera guerra mundial y de la Revolución rusa. La Declaración de Ginebra consta de cinco principios que protegen los siguientes derechos: condiciones adecuadas para el desarrollo material y espiritual; alimentación; atención sanitaria; ayudas especiales para los niños con problemas de tipo síquico o social; protección en situaciones de emergencia; y protección ante cualquier tipo de explotación. Años más tarde, en 1959, la Asamblea General de Naciones Unidas adopta la Declaración de Derechos del Niño, cuyo fin es especificar los derechos de la Declaración Universal de los Derechos Humanos para los niños. El documento consta de un preámbulo y diez principios que reconocen ciertos derechos, aunque no es un texto jurídicamente vinculante. Los derechos plasmados en la Declaración son: 1) derecho al disfrute de todos los derechos sin discriminación; 2) derecho a la protección y consideración del interés supe-

1 Perrot, Michelle, "Figuras y funciones", en Ariès, Phillipe y Duby, Georges (dirs.), Historia de la vida privada, Madrid, Taurus, 1993, t. 4, pp. 128 y 129. 
rior del niño; 3) derecho a un nombre y una nacionalidad; 4) derecho a la salud, alimentación, vivienda recreo y servicios médicos; 5) derecho del niño física o mentalmente impedido a recibir atención especial; 6) derecho a la vinculación afectiva y a no separarse de sus padres; 7) derecho a la educación, al juego y recreaciones; 8) derecho a la prioridad en protección y socorro; 9) protección contra abandono, crueldad y explotación; 10) protección en contra de la discriminación. Ambas declaraciones tienen contenidos claramente proteccionistas, pues se interpretan los derechos simplemente como obligaciones exigidas a las personas o a las instituciones. ${ }^{2}$

Finalmente, a partir de una iniciativa de Polonia que pretendía dar a la Declaración de 1959 el carácter de Convención — para hacerla jurídicamente vinculante-, el 20 de noviembre de 1989 se aprueba por la Asamblea General de Naciones Unidas la Convención sobre los Derechos del Niño. Este instrumento internacional constituye en la actualidad la base del reconocimiento de la titularidad de derechos de niños, niñas y adolescentes en el ámbito internacional e interno de los países que lo han ratificado. $^{3}$

\section{LOS DERECHOS DE NIÑOS, NIÑAS Y ADOLESCENTES EN EL SISTEMA JURÍDICO MEXICANO}

El Estado mexicano ratificó la Convención sobre los Derechos del Niño en 1990, de manera que, según el artículo 133 constitucional, a partir de este momento sus disposiciones se incorporaron al orden jurídico mexicano. Pese a ello, el texto constitucional no sufrió modificación alguna, aunque el estatus jurídico de los menores de 18 años en el instrumento internacional implicaba una drástica transformación. No fue sino hasta 2000 que el artículo 4o. fue reformado y por primera vez

2 Ochaíta, Esperanza y Espinosa, María Ángeles, Hacia una teoría de las necesidades infantiles y adolescentes: necesidades y derechos en el marco de la Convención de Naciones Unidas sobre Derechos del Niño, McGrawHill-UNICEF, 2004, pp. 428 y 429.

3 La Convención sobre los Derechos del Niño es el instrumento internacional más ratificado en la historia, siendo los únicos países faltantes Estados Unidos y Somalia. A diferencia de la Declaración, se trata de un catálogo de derechos muy completo, que consta de 54 artículos en los que se establece además, el mecanismo para verificar el cumplimiento de las obligaciones de los Estados parte a través de la rendición del informes periódicos al Comité de Derechos del Niño. 
se reconoció a los niños y niñas como titulares de derechos a nivel constitucional.

La primera reforma al artículo 4o. de la Constitución se promulgó en el Diario Oficial del 31 de diciembre de 1974, en ella se establece la igualdad jurídica del varón y la mujer; la protección legal de la organización de la familia, y la paternidad responsable:4 "El varón y la mujer son iguales ante la ley. Ésta protegerá la organización y el desarrollo de la familia... Toda persona tiene derecho a decidir de manera libre, responsable e informada sobre el número y espaciamiento de sus hijos".

Desde la perspectiva tradicional (anterior a la Convención), la tutela legal de la familia era suficiente para garantizar la protección de los niños y adolescentes. Evidentemente la redacción de esta primera reforma no recoge la concepción de los niños como titulares de derechos, en parte debido a que se trata de un texto anterior a la Convención, pero también a causa de la imagen de la familia como espacio privado en el que los padres tienen poder de disposición sobre los hijos, idea que prevaleció durante mucho tiempo y apenas recientemente ha comenzado a cambiar. Según algunos autores, la adscripción del niño a la esfera familiar fue una forma de privatizar su estatus:

La desigualdad material, por su parte, era, para los niños, una desigualdad derivada de su pertenencia a la familia. La incardinación del niño en la familia era una forma de privatizar su estatus. De tal modo que la desigualdad social de los niños, tanto en las oportunidades como en los resultados, no aparecía como un problema específico, sino como una condición natural. ${ }^{5}$

La siguiente reforma constitucional respecto de la protección de los "menores de edad"6 se publicó el 18 de marzo de 1980, a partir de la iniciativa presentada en noviembre del 1979 en el contexto del Año Interna-

4 Madrazo, Jorge, “Artículo 4o.”, Derechos del Pueblo Mexicano, México, Cámara de Diputados, Senado de la Republica, Poder Judicial de la Federación, TE, IFE, Porrúa, 2006, p. 187.

5 Hierro, Liborio L., "Los derechos de la infancia, razones para una ley", Estudios Jurídicos en homenaje al profesor Aurelio Menéndez, Madrid, Cívitas, 1996, vol. IV, p. 5480 .

6 Es necesario aclarar que se habla de protección de los niños y niñas, pues la regulación sobre los menores en conflicto con la ley penal tiene una historia independiente, aunque relacionada, debido a que comparte los mismos paradigmas culturales sobre la minoridad. 
cional del Niño. ${ }^{7}$ En ésta se advierte una importante transformación, pues de manera muy incipiente aparecen los niños como destinatarios de ciertas obligaciones de los padres. En el texto se percibe una concepción del menor como sujeto de protección, pues no tiene derechos en sí, sino que se limita a recibir los cuidados derivados de los deberes vinculados con la filiación. Se establece la obligación de los padres para satisfacer las necesidades y preservar la salud física y mental de los niños y se deja a la ley la determinación de la actuación de las instituciones públicas en apoyo de los menores. ${ }^{8}$

Es deber de los padres preservar el derecho de los menores a la satisfacción de sus necesidades y a la salud física y mental. La Ley determinará los apoyos a la protección de los menores, a cargo de las instituciones públicas.

Del texto se desprende todavía la idea de que la atención de los niños corresponde al ámbito privado, mientras que la actuación pública opera de manera subsidiaria y restringida por la ley. Llama poderosamente la atención la total ausencia de cualquier consideración directa o indirecta a los niños en situación de abandono, es decir, excluidos del ámbito familiar, aquellos cuya familia no estaba en posibilidad de atender o simplemente carecían de ésta. El texto constitucional se limitó durante muchos años a establecer ciertos mecanismos de protección en el contexto de la familia. Los niños que estaban relegados del mismo simplemente carecían de dispositivos constitucionales de tutela. Se dejó a la ley secundaria la regulación de los apoyos que habían de darse por parte de las instituciones públicas a los "menores". 9

Esta situación no es exclusiva de México, ni es atribuible a una simple omisión del legislador. La separación de la infancia en dos universos distintos de acuerdo con su inclusión en una familia forma parte de lo que en América Latina ha sido calificado por García Méndez como la doctrina de la situación irregular. Según este autor, el tratamiento jurídico a la infancia estaba determinado por su pertenencia a dos instituciones: la escuela y la familia, que marcaban una distinción entre "niños" y "menores":

7 La Asamblea General de las Naciones Unidas declaró 1979 como el Año Internacional del Niño, al conmemorarse los 20 años de la Declaración de 1959.

8 Madrazo, Jorge, op. cit., nota 4, pp. 187 y 188.

9 Ibidem, p. 159. 
... Estas leyes presuponen la existencia de una profunda división al interior de la categoría infancia: niños-adolescentes y menores (entendiéndose por estos últimos el universo de los excluidos de la escuela, la familia, la salud, etcétera). En consecuencia estas leyes, que son exclusivamente de y para los menores, tienden objetivamente a consolidar las divisiones aludidas dentro del universo infancia. ${ }^{10}$

Además, la redacción de la norma legal tenía otra consecuencia importante respecto de otra realidad de los niños: la de aquellos cuyos padres no satisfacían sus necesidades e incluso eran víctimas de maltrato en el propio seno familiar por parte de alguno de ellos. La privatización del status del niño otorgaba tácitamente (y en algunas ocasiones explícitamente) $)^{11}$ a los padres casi total discrecionalidad en la forma de satisfacer las obligaciones respecto de los hijos, incluyendo prácticas que hoy catalogamos como violencia contra los niños. ${ }^{12}$

El maltrato supone ejercer violencia física o síquica, de forma no accidental. Se podría decir que en otras épocas el trato dispensado a los niños era mucho más duro que en la actualidad y, por ejemplo, los castigos físicos eran muy

10 García Méndez, Emilio, Infancia-Adolescencia. De los derechos y de la justicia, México, Distribuciones Fontamara, 2001, p. 22. El autor se refiere a las legislaciones minoristas latinoamericanas basadas en la llamada "doctrina de la situación irregular" que hacían distinción entre "menores" y "niños-adolescentes".

11 Tal era el caso del llamado "derecho de corrección" derivado de la patria potestad y que anteriormente se interpretaba incluso como una facultad para ejercer violencia contra el niño o adolescente. Este derecho sigue vigente en el Código Civil Federal mexicano, aunque el mismo artículo que lo establece aclara que excluye el derecho a inflingir daños contra su integridad física o síquica: artículo 423: "Para los efectos del artículo anterior, quienes ejerzan la patria potestad o tengan menores bajo su custodia, tienen la facultad de corregirlos y la obligación de observar una conducta que sirva a éstos de buen ejemplo.

"La facultad de corregir no implica inflingir al menor actos de fuerza que atenten contra su integridad física o síquica, en los términos de lo dispuesto por el artículo 323 ter de este Código".

12 Ochaíta y Espinosa definen el maltrato de la siguiente manera: "Maltratar a un niño significa, en definitiva, no satisfacer sus necesidades adecuadamente, no ofrecerle las condiciones básicas que garanticen su bienestar y posibiliten su desarrollo", Ochaíta, Esperanza y Espinosa, Ma. Ángeles, "Dificultades en el desarrollo de origen social: definición, incidencia, tipos y consecuencias del maltrato infantil”, en García Sánchez, J. N. (comp.), Intervención psicopedagógica en trastornos del desarrollo, Madrid, Pirámide, 1999, pp. 354 y 355. 
frecuentes en la casa y en la escuela. Las conductas infantiles consideradas inadecuadas se reprimían con enorme dureza. ${ }^{13}$

La última reforma al artículo 4o. se realizó el 7 de abril de 2000, sustituyendo el quinto párrafo por tres nuevos párrafos que se incorporaron al texto del artículo. La nueva redacción modificó radicalmente el status constitucional de los niños y niñas, pues se les menciona por primera vez, remplazando al término "menores" utilizado en el texto anterior. El artículo reconoce el derecho a la satisfacción de las necesidades, describiendo cuáles son éstas: alimentación, salud, educación y sano esparcimiento para su desarrollo integral, además de que incorpora a nuevos agentes obligados al cumplimiento de estos derechos, ascendientes, tutores y custodios además de los padres. Asimismo, señala al Estado como obligado a propiciar el respeto a la dignidad del niño y el ejercicio de los derechos. Finalmente, define el deber del Estado respecto de los particulares involucrados en el cumplimiento de los derechos de los niños: ${ }^{14}$

Los niños y las niñas tienen derecho a la satisfacción de sus necesidades de alimentación, salud, educación y sano esparcimiento para su desarrollo integral.

Los ascendientes, tutores y custodios tienen el deber de preservar estos derechos. El Estado proveerá lo necesario para propiciar el respeto a la dignidad de la niñez y el ejercicio pleno de sus derechos.

El Estado otorgará facilidades a los particulares para que coadyuven al cumplimiento de los derechos de la niñez.

En el dictamen relativo a la iniciativa de reforma, se reconoce que la redacción originada en la reforma de 1980 al artículo 4o. respecto de los derechos del niño, era insuficiente para responder a las exigencias de la realidad y para la protección de las necesidades de los niños y niñas. ${ }^{15} \mathrm{El}$ objetivo de la reforma constitucional es adecuar el marco jurídico de los niños y niñas a los postulados internacionales. Con este

13 Delval, Juan, "Algunas reflexiones sobre los derechos de los niños", Infancia y sociedad, Madrid, 27-28, Ministerio de Asuntos Sociales, Dirección General del Menor y la Familia, 1994, p. 25.

14 Madrazo, Jorge, op. cit., nota 4, p. 159.

15 Derechos del Pueblo Mexicano: Reformas constitucionales durante la LVII Legislatura (1997-2000), México, Cámara de Diputados, Senado de la República, Poder Judicial de la Federación, TE, IFE, Porrúa, 2006, t. XIII, p. 768. 
mismo propósito, en mayo de 2000 se publicó la ley reglamentaria del párrafo sexto del artículo 4o.: Ley para la Protección de los Derechos de las Niñas, Niños y Adolescentes. El objeto de la referida ley es "garantizar a niñas, niños y adolescentes la tutela y el respeto de los derechos fundamentales reconocidos en la Constitución". ${ }^{16}$ En el mismo ordenamiento se establece la distinción entre niñas, niños y adolescentes (artículo 2o.), ${ }^{17}$ el objetivo de la protección de los derechos y los principios rectores de esta Ley (artículo 3o.), ${ }^{18}$ así como la obligación de los distintos niveles de gobierno en el cumplimiento de la ley y la norma constitucional (artículo 5o.). La Ley establece un catálogo amplio de derechos relacionados con el párrafo cuarto destinados a las personas menores de 18 años en México. ${ }^{19}$

\section{LA REFORMA CONSTITUCIONAL PENDIENTE EN MATERIA DE DERECHOS DE NIÑOS, NIÑAS Y ADOLESCENTES}

Pese al enorme avance que significó la reforma al artículo 4o. del año 2000, el texto constitucional continúa siendo insuficiente en el reconocimiento de los derechos de los niños y niñas. Aunque la Convención recoge un catálogo amplísimo de derechos y libertades, la Constitución se limita a reconocer el derecho a la satisfacción de ciertas necesidades. La deficiencia más notable se da respecto de las libertades y los derechos de participación, es decir, los derechos civiles y políticos que, paradójicamente, constituyen la primera generación histórica de derechos huma-

16 Artículo 1o. de la Ley para la Protección de los Derechos de Niñas, Niños y Adolescentes.

17 El artículo 2o. establece que: "Para los efectos de esta Ley, son niñas y niños las personas de hasta 12 años incompletos, y adolescentes los que tienen entre los 12 años cumplidos y 18 años incumplidos".

18 Los principios rectores de la protección de los derechos de niñas, niños y adolescentes según el artículo 3o. de la Ley para la Protección de los Derechos de Niñas, Niños y Adolescentes son: interés superior de la infancia, no discriminación, igualdad, vida en familia, vida libre de violencia, corresponsabilidad de los miembros de la familia, Estado y sociedad y tutela plena e igualitaria de los derechos humanos y de las garantías constitucionales.

19 Una de las críticas que se han formulado a la Ley para la Protección de los Derechos de Niñas, Niños y Adolescentes es que se limita a repetir y desarrollar los derechos contenidos en la Convención sobre los Derechos del Niño, sin crear los mecanismos necesarios para la garantía y restitución de estos derechos. 
nos. ${ }^{20}$ Otros aspectos son igualmente deficientes en el actual texto constitucional, lo que da cuenta de la necesidad de una reforma que recoja las características relevantes de los derechos de niños y niñas, así como los principios que deben orientar su interpretación.

Ciertamente, como señalan algunos autores, los principios relativos a la protección de derechos de niños, niñas y adolescentes se encuentran recogidos en la Ley Reglamentaria del Artículo 4o.; sin embargo, al no estar contemplados constitucionalmente no son susceptibles de ser protegidos mediante los mecanismos de garantía previstos en la norma fundamental. Por esta misma razón, no pueden ser considerados pautas rectoras de la legislación inferior por estar en el mismo rango que ésta, además de que, al estar contenidos en una norma secundaria, pierden fuerza como criterio de ponderación en caso de conflicto entre dos derechos reconocidos constitucionalmente. Por otra parte, no todos los principios aparecen explícitamente mencionados en la Convención, sino que algunos de ellos derivan de la interpretación del Comité de Derechos del Niño y de la doctrina desarrollada a partir de la entrada en vigor del instrumento internacional y de su incorporación a las Constituciones de diferentes países del mundo.

Otro conflicto que hace necesaria la modificación del artículo 4o. es el derivado de la reforma al artículo 18 constitucional en 2005, pues ha provocado falta de claridad respecto de los términos "niño" y "adolescente", así como el alcance de las normas de protección de derechos.

Lo anterior justifica la necesidad de un cambio en el texto constitucional que incorpore los criterios de interpretación y ponderación derivados de la legislación, la práctica y la doctrina internacionales respecto de los derechos de los niños, niñas y adolescentes. Los elementos básicos que debería contemplar dicha reforma son los siguientes:

20 La llamada "primera generación de derechos" se entiende compuesta por los derechos relacionados con la libertad, positiva y negativa. En esta primera generación quedarán comprendidos los llamados "civiles y políticos" que se concretan en la vida, el honor, la libertad de conciencia, pensamiento y expresión, las garantías procesales — proceso legal, presunción de inocencia, derecho de defensa-, la seguridad jurídica, el derecho de propiedad, así como el derecho al voto y a la participación política. 


\section{Cambio de ubicación de los derechos de niños, niños y adolescentes del actual artículo 4o. constitucional}

La primera modificación que requeriría el texto constitucional actual respecto de los derechos durante la infancia y adolescencia, sería su exclusión del actual artículo 4o. para situarlo en otro numeral, preferentemente dedicado exclusivamente a los derechos de los niños y adolescentes. El artículo 4o. en vigor reconoce la igualdad entre el varón y la mujer, la protección de la familia, el derecho a la libre procreación, el derecho a la protección de la salud, a un medio ambiente sano y a la vivienda en sus primeros cinco párrafos; los párrafos 6,7 y 8 son los destinados al reconocimiento de los derechos de niñas, niños y adolescentes. Como se puede apreciar, el artículo mencionado se ha convertido en una especie de "cajón de sastre" que reúne diversos derechos que nada tienen que ver entre sí. Entre éstos se encuentran los derechos de los niños.

Otro inconveniente de la redacción vigente del artículo es la regulación conjunta de la protección de la organización y el desarrollo de la familia (aunque sea entre otros muchos derechos) ${ }^{21}$ y los derechos de los niños, pues se entiende que existe una relación de subordinación. Esto se ve reafirmado con el párrafo 7 que habla de las obligaciones de los ascendientes. Precisamente el objetivo de situar los derechos de los niños en el artículo 4o. fue el reconocimiento de la familia como el eje sobre el que gira la sociedad ${ }^{22}$ y vincularlos así con los deberes de los progenitores. El cambio de paradigma explicado con anterioridad, es decir, el paso de la situación irregular a la protección integral, aconseja justamente cambiar su posición en el articulado constitucional. Lo anterior no significa en modo alguno desconocer la importancia de la familia o de las libertades de ésta, ni de los derechos de los padres respecto de la formación y educación de los hijos. Sin embargo, se requiere hacer notar que se trata de dos esferas independientes y que en modo alguno los derechos de los niños y niñas se encuentran supeditados a la autoridad familiar. Se trata de derechos directamente frente al Estado, aunque por su condición de desarrollo los niños se encuentren inmersos en la esfera familiar. Los

21 El derecho a la vivienda del párrafo 5 del mismo artículo 4o. se vincula también a la familia: "Toda familia tiene derecho a disfrutar de vivienda digna y decorosa. La ley establecerá los instrumentos y apoyos necesarios a fin de alcanzar tal objetivo".

22 Derechos del Pueblo Mexicano: Reformas constitucionales durante la LVII Legislatura (1997-2000), op. cit., nota 15, p. 752. 
derechos vinculados a la familia difieren de los derechos que a niños y adolescentes les corresponden como personas. Unos son los derechos del niño en la familia, que comprenden una serie de deberes y derechos en el seno doméstico, como el derecho mismo a vivir en familia, a participar en las decisiones concernientes a ésta, a mantener contacto con ambos progenitores, etcétera, y otros son los derechos del niño frente al Estado, aunque evidentemente éstos estén en cierto grado mediados por los padres, como serían el derecho a la intimidad, ${ }^{23}$ el derecho a la información, la libertad de expresión, etcétera:

Tenemos así que tratándose de los derechos humanos en la familia, en especial de los niños, convergen tres actores fundamentales que tienen alguna responsabilidad en el ejercicio: el niño como titular de derechos, los padres como obligados primarios del ejercicio de estos derechos, pero al mismo tiempo con derechos propios derivados de los deberes de crianza y finalmente el Estado como responsable último de que el niño y adolescente esté protegido y a la vez encargado de reconocer y respetar los derechos de los padres. $^{24}$

\section{Definición de niño, niña y adolescente}

Aunque en la Ley reglamentaria del artículo 4o. se establece la distinción entre niño y adolescente, se requiere que esta diferencia se reco-

23 El derecho a la intimidad es un ejemplo de un derecho específico de los niños que se interpreta con un contenido distinto al derecho a la intimidad una vez que se ha alcanzado la mayoría de edad. Durante la infancia se trata de un ámbito indisponible al que nadie puede ingresar, ni siquiera con consentimiento del titular o de sus representantes; en el caso de los adultos, por el contrario, se entiende como un derecho de disposición. De acuerdo con Hierro... en atención al desarrollo evolutivo de la inteligencia y la voluntad, muchos derechos que, en el adulto, asumen la estructura de un poder de disposición, en los menores de edad y en los incapaces asumen la estructura de un derecho obligatorio no activo, es decir, de un derecho a ser tratado, en todo caso, de cierto modo (Hierro, Liborio, "La intimidad de los niños: Un test para el derecho a la intimidad", en Sauca, José Ma. (ed.), Problemas actuales de los derechos fundamentales, Madrid, Universidad Carlos III de Madrid, Boletín Oficial del Estado, 1994, p. 390).

24 González Contró, Mónica, "Los derechos fundamentales del niño en el contexto de la familia", en Álvarez de Lara, Rosa Ma. (coord.), Panorama internacional de derecho de familia: Culturas y sistemas jurídicos comparados, México, UNAM, Instituto de Investigaciones Jurídicas, 2006, p. 75. 
nozca a nivel constitucional y que igualmente se definan los alcances de la protección de los derechos.

La diferenciación entre la infancia y adolescencia como etapas evolutivas con características diversas, aunque también con cualidades compartidas, ha sido reconocida desde hace mucho tiempo por las disciplinas dedicadas del estudio de la evolución humana. Por un lado, se reconoce que el inicio de la adolescencia está marcado por una serie de cambios físicos y síquicos que llevan al ser humano a vivir un periodo de transición que le preparará para la vida adulta y que le hace capaz de tener una mayor autonomía en la toma de decisiones. ${ }^{25}$ Lo anterior no implica dejar de reconocer que, pese a las capacidades adquiridas al momento de ingresar a la adolescencia, ésta se caracteriza, al igual que la infancia, por ser un período de desarrollo que requiere de satisfactores especiales y, por ende, de una equivalente protección de derechos a los de los primeros años de la vida humana: "los cambios que se producen en esta etapa, cuantitativamente, se dan en una mayor proporción y, cualitativamente, se asiste al desarrollo de una nueva organización sicológica y social". ${ }^{26}$

Nos encontramos así que la distinción entre infancia y adolescencia obedece a razones plenamente justificadas que pueden ayudar a la garantía de los derechos mediante el reconocimiento, por ejemplo, de una mayor autonomía a partir del inicio de la pubertad. Esta distinción debe recogerse constitucionalmente para ser identificada como un principio de interpretación de los derechos de niños, niñas y adolescentes.

Además de las razones planteadas, se requiere la modificación constitucional debido a que, a partir de la reforma al artículo 18 en 2005, el término "adolescente" quedó incorporado al lenguaje de la Constitución, generando así falta de coherencia con el actual artículo 4o. El artículo 18 ordena la creación de un nuevo sistema de justicia para adolescentes, definiendo a éstos como aquellas personas que tengan "entre doce años

25 Aunque ciertamente los expertos concluyen que el proceso de desarrollo se da de forma distinta en cada persona, sin que sea posible fijar criterios universales infalibles que determinen el grado de autonomía o la totalidad de capacidades alcanzadas. Sin embargo, jurídicamente se requiere de establecer un criterio universal que determine el paso de una etapa a otra.

26 Moreno, Amparo, Barrio del, Cristina, La experiencia adolescente. A la búsqueda de un lugar en el mundo, Buenos Aires, Sigue, 2000, p. 17. 
cumplidos y menos de dieciocho años de edad". ${ }^{27}$ El resultado de esto es que la Constitución contiene un doble criterio, pues por una parte se entiende que el artículo 4o. protege a todos las personas menores de 18 años identificándolas como niños y niñas, utilizando la norma de la Convención pero sin definirlo expresamente, y en el artículo 18 se crea un nuevo concepto jurídico - “adolescente"-, que está incluido también en la franja de edad por debajo de los 18 años.

Algunos autores han llegado incluso a sostener que con la reforma al artículo 18 se excluyó de la protección de derechos contenida en el artículo 4o. a las personas mayores de 12 y menores de 18 años. Aunque esta interpretación es fácilmente rebatible recurriendo a una comprensión coherente del marco jurídico de la infancia (sobre todo la Convención sobre los Derechos del Niño y la Ley de Protección de Derechos) en la que queda perfectamente claro que la tutela de los derechos llega hasta antes de cumplir los 18 años, una adecuada técnica legislativa aconseja-

27 El término "adolescente" aparece en los párrafos 5 y 6 del actual artículo 18 de la Constitución Federal:

"La Federación, los estados y el Distrito Federal establecerán, en el ámbito de sus respectivas competencias, un sistema integral de justicia que será aplicable a quienes se atribuya la realización de una conducta tipificada como delito por las leyes penales y tengan entre doce años cumplidos y menos de dieciocho años de edad, en el que se garanticen los derechos fundamentales que reconoce esta Constitución para todo individuo, así como aquellos derechos específicos que por su condición de personas en desarrollo les han sido reconocidos. Las personas menores de doce años que hayan realizado una conducta prevista como delito en la ley, sólo serán sujetos a rehabilitación y asistencia social.

"La operación del sistema en cada orden de gobierno estará a cargo de instituciones, tribunales y autoridades especializados en la procuración e impartición de justicia para adolescentes. Se podrán aplicar las medidas de orientación, protección y tratamiento que amerite cada caso, atendiendo a la protección integral y el interés superior del adolescente.

"Las formas alternativas de justicia deberán observarse en la aplicación de este sistema, siempre que resulte procedente. En todos los procedimientos seguidos a los adolescentes se observará la garantía de debido proceso legal, así como la independencia entre las autoridades que efectúen la remisión y las que impongan las medidas. Éstas deberán ser proporcionales a la conducta realizada y tendrán como fin la reintegración social y familiar del adolescente, así como el pleno desarrollo de su persona y capacidades. El internamiento se utilizará sólo como medida extrema y por el tiempo más breve que proceda, y podrá aplicarse únicamente a los adolescentes mayores de catorce años de edad, por la comisión de conductas antisociales calificadas como graves". 
ría definir estos nuevos términos incorporados al lenguaje constitucional para hacer explícito el alcance de cada norma jurídica.

\section{Enunciación de los principios rectores de la Convención} de los Derechos del Niño como criterios de interpretación y aplicación de los derechos

Desde la firma de la Convención de los Derechos del Niño se reconoció que la interpretación de este tipo específico de derechos debe obedecer a ciertos principios que se desprenden del mismo instrumento jurídico, así como de la justificación de los derechos. Entre éstos podemos mencionar el interés superior del niño y adolescente, la autonomía progresiva, el derecho a la supervivencia y al desarrollo integral y el principio de prioridad. ${ }^{28}$

El interés superior del niño está contemplado en el artículo 3o. de la Convención y fue reconocido por el Comité de los Derechos del Niño en su primera sesión. Se le ha definido como una disposición paraguas que ha de seguirse en todas las acciones que conciernen a los niños ${ }^{29}$ y que por tanto abarca al resto de los derechos contenidos en este instrumento: "Se trata de asegurar por parte de los Estados que, en cualquier proceso de toma de decisiones que afecte a la infancia y la adolescencia, han de tenerse en cuenta de forma prioritaria sus intereses". ${ }^{30}$

La noción de "interés superior del niño" se menciona también explícitamente en otros artículos de la Convención: 9o., 18, 20, 21, 37 y 40. Para Hierro, se trata de un principio general de discriminación inversa a favor del niño que implica la responsabilidad subsidiaria del Estado en la satisfacción de los derechos:

28 Esta lista difiere de los principios que menciona la Ley para la Protección de los Derechos de las Niñas, Niños y Adolescentes en su artículo 3o., ya que éstos, tal como menciona el mismo artículo, pretenden ser principios rectores de la protección de los derechos de niñas, niños y adolescentes, mientras que la norma constitucional tiene como fin establecer principios rectores de las leyes, instituciones y políticas relacionadas con la infancia. Es evidente también que no se contraponen, al tratarse de normas jurídicas de distinta naturaleza y jerarquía.

29 Alston, Philip y Wash Bridget, Gilmour, "The Best Interests of the Child. Toward a Synthesis of Children's Rights and Cultural Values”, en Verdugo, Miguel Ángel y Soler-Sala, Víctor (eds.), La Convención de los Derechos del Niño. Hacia el siglo XXI, Universidad de Salamanca, 1996, p. 257.

30 Ochaíta, Esperanza y Espinosa, María Ángeles, op. cit., nota 2, p. 433. 
Se trata del principio del "interés superior del niño" que convierte al Estado en responsable subsidiario de la satisfacción de los derechos del niño cuando los padres, tutores u otros responsables incumplan estos deberes y que se enuncia además como principio inspirador de la conducta de las instituciones privadas o públicas, de los tribunales, de las autoridades administrativas e incluso de los órganos legislativos. Significa esto, a mi entender, que el principio humanitario primitivo en favor de los niños, que ya contenía la Declaración de Ginebra para casos de desastre, se convierte ahora en principio inspirador y jerarquizador del reconocimiento jurídico de los derechos de los niños. ${ }^{31}$

El principio de autonomía progresiva prescribe el reconocimiento de la capacidad de autodeterminación como una aptitud que se va desplegando gradualmente a lo largo de la vida. De acuerdo con esta interpretación, se debe conceder facultad para decidir sobre los asuntos que conciernen al individuo en la medida en que va alcanzando cierto grado de madurez. Así, la ley debe hacer distinciones entre las etapas de desarrollo en relación con los asuntos en que el individuo tiene capacidad para intervenir. La competencia para decidir con cuál de los padres quiere vivir el niño en un proceso de divorcio o la necesidad del consentimiento para la formalización de la adopción a partir de cierta edad, constituyen ejemplos de la aplicación de este principio en la legislación. De igual manera, la idea de autonomía progresiva debe ser considerada en la aplicación de cualquier derecho del niño o adolescente.

El derecho a la supervivencia y al desarrollo integral es otro de los principios indispensables en la interpretación de las disposiciones que contienen derechos de los niños, así como servir de criterio para orientar la actuación de cualquier autoridad relacionada con la infancia y adolescencia. Este principio debe entenderse como la condición necesaria en el cumplimiento de otros derechos y por ello no se limita a la mera sobrevivencia, sino que se extiende a la pretensión de acceso a los satisfactores para atender a las necesidades básicas, con una función directa y subsidiaria del Estado como agente, y un deber en la asignación de recursos en el desempeño de este papel.

El derecho a la supervivencia se incorporó a pedido de la India y del UNICEF. Este concepto se basa en la realidad y en la propia experiencia

31 Hierro, Liborio, ¿ ¿Tienen los niños derechos? Comentario a la Convención sobre los Derechos del Niño”, Revista de Educación, Madrid, núm. 294, enero-abril de 1991, p. 232. 
de los organismos internacionales, que intentan asegurar que el niño no sólo nazca, sino que además tenga la oportunidad de "sobrevivir". No se contrapone el concepto de "supervivencia" con el de "desarrollo" de los países desarrollados. Se trata más bien de cuestiones complementarias, y si bien el concepto mismo de supervivencia no tiene una base legal establecida, ya ha sido utilizado en la práctica por el UNICEF y el Banco Mundial. Respecto del tema de la personalidad del niño, se incluyó para despejar dudas sobre el alcance de la noción de supervivencia, que efectivamente podría entenderse sólo como relativo a situaciones de emergencia. $^{32}$

El principio de prioridad se encuentra reconocido en la Ley para la Protección de los Derechos de Niñas, Niños y Adolescentes en el artículo 14 como un derecho. Sin embargo, la descripción de este derecho tiene un alcance más limitado que su formulación como principio, que funciona precisamente como un criterio de ponderación entre normas constitucionales. En la ley secundaria este derecho comprende que se les asegure prioridad en el ejercicio de los derechos, especialmente a que:

1. Se les brinde protección y socorro en cualquier circunstancia y con la oportunidad necesaria.

2. Se les atienda antes que a los adultos en todos los servicios, en igualdad de condiciones.

3. Se considere el diseñar y ejecutar las políticas públicas necesarias para la protección de sus derechos.

4. Se asignen mayores recursos a las instituciones encargadas de proteger sus derechos.

Como se desprende del texto citado, el derecho tiene un alcance limitado por los supuestos previstos en el artículo. En realidad, el único inciso que contempla un verdadero derecho de prioridad es el B al establecer que en igualdad de condiciones, los niños deben ser atendidos antes que los adultos. El resto de las fracciones se limita a establecer algunas acciones para dar efectividad a los derechos.

El principio de prioridad derivado de una interpretación holística de la Convención prescribe en cambio que, ante un posible conflicto de dere-

32 Bárcena, Andrea, Textos de derechos humanos sobre la niñez, México, Comisión Nacional de Derechos Humanos, 1992, p. 187. 
chos, debe prevalecer el derecho del niño. Este criterio de ponderación permite resolver casos concretos especialmente importantes para los niños y adolescentes, sin los cuales el contenido de la Convención y demás instrumentos jurídicos sería nugatorio: por ejemplo, en caso de un enfrentamiento entre el derecho del niño a tener una familia en la que pueda desarrollarse plenamente y el pretendido derecho de una pareja a adoptar un niño, permite inclinarse para preservar el derecho del niño en el caso de que haya dudas de que la pareja tenga las habilidades necesarias para criarlo adecuadamente. Ante el conflicto entre el derecho a la información de los ciudadanos y el derecho a la intimidad de un adolescente que ha cometido una conducta tipificada como delito, prevalece el derecho a la intimidad del último. Evidentemente que el apego a este principio no supone que en todos los casos debe prevalecer el derecho del niño, se trata simplemente de un criterio orientador de las decisiones de la autoridad, ya sea judicial, administrativa o legislativa:

En la ponderación, en efecto, hay siempre razones en pugna, intereses o bienes en conflicto, en suma, normas que nos suministran justificaciones diferentes a la hora de justificar una decisión. Ciertamente, en el mundo del derecho el resultado de la ponderación no ha de ser necesariamente el equilibrio entre tales intereses, razones o normas; al contrario, lo habitual es que la ponderación desemboque en el triunfo de alguno de ellos en el caso concreto. ${ }^{33}$

\section{Reconocimiento de la titularidad de los derechos constitucionales,} además de los derechos especificos, particularmente el derecho a expresar su opinión y a intervenir en las decisiones que le conciernen, así como derecho a la protección especial del Estado contra toda forma de maltrato, abandono y abuso

Aunque podría parecer tautológico e irrelevante el reconocimiento de los niños, niñas y adolescentes como titulares de los derechos constitucionales debido a que el artículo 1o. señala que todo individuo gozará de las garantías que otorga la Constitución, se requiere hacer esta precisión por dos razones:

33 Prieto Sanchís, Luis, "Neoconstitucionalismo y ponderación judicial", en Carbonell, Miguel (coord.), Neoconstitucionalismo(s), Madrid, Trotta, 2003, p. 137. 
En primer lugar, como se ha expuesto al inicio de este texto, tradicionalmente se excluyó a los niños de la titularidad de derechos, debido principalmente a su pertenencia a la familia. Se entendía que el acceso a los satisfactores estaba garantizado por los padres, de modo que la garantía de los derechos fundamentales a los ascendientes repercutía automáticamente en el beneficio del niño. El caso de los niños en situación de abandono también ha sido ya tratado, pues en estas situaciones el Estado intervenía convirtiendo a los pequeños en "menores" y sometiéndolos a su tutela. Esta condición cambió con la firma de la Convención sobre los Derechos del Niño, aunque todavía hoy se trata de un debate no resuelto entre los teóricos de los derechos subjetivos. ${ }^{34}$

En el ámbito del derecho positivo podemos ejemplificar la segunda causa - muy vinculada con la primera - que justifica la importancia de hacer explícita la titularidad de los derechos pese al ya mencionado artículo 10.: el ejercicio e incluso la titularidad de algunos derechos durante la minoría de edad es francamente dudoso o por lo menos difiere de las características que reviste cuando se trata de los adultos. Por ejemplo, la libertad de profesión o trabajo ¿puede aplicarse a los niños y niñas? ¿el derecho a la información, a la libertad de escribir y difundir escritos o el derecho de petición se interpretan aplicables de la misma manera a los niños que a los adultos? Continuando con el texto constitucional ¿el derecho de asociación, a poseer armas en el domicilio o la libertad de trán-

34 El debate más representativo en relación con la titularidad de los derechos del niño se vincula con la explicación de lo que significa tener un derecho subjetivo. Tradicionalmente se han dado dos tipos de respuesta a este cuestionamiento, representados en las teorías de la voluntad y las teorías del interés. La teoría de la voluntad como explicación de los derechos subjetivos sostiene que tener un derecho es tener un ámbito jurídicamente protegido en el que el titular puede actuar como pequeño soberano y decidir entre exigirlo o renunciar a su cumplimiento, en otras palabras, se trata de un poder de disposición sobre el sujeto obligado por el derecho. Por su parte, la teoría del interés concibe a los derechos como intereses jurídicamente protegidos. La teoría de la voluntad es incapaz de explicar los derechos de los niños, pues es precisamente uno de sus rasgos característicos el que la voluntad del titular no interviene en el ejercicio, sino que son de cumplimiento obligatorio. En cambio, los derechos de los niños sí son susceptibles de entenderse como intereses protegidos mediante una norma. MacCormick, Neil, "Los derechos de los niños: una prueba para las teorías del derecho", Derecho legal y socialdemocracia, Madrid, Tecnos, 1990, pp. 129-137. Con base en estos argumentos, algunos teóricos voluntaristas niegan la titularidad de derechos en los niños, niñas y adolescentes por su incapacidad para renunciar al ejercicio de los mismos. 
sito son realmente derechos de los niños y adolescentes? ¿qué pasa con la libertad de conciencia, creencia y religión?35

La explicación de esta aparente incompatibilidad la podemos encontrar en el origen mismo de la idea de derechos humanos: la llamada "primera generación de derechos" surgida a finales del siglo XIX aparece indisolublemente ligada a la noción de autonomía personal, cualidad que se entiende ausente durante los primeros años de la vida humana. En efecto, los derechos civiles y políticos tienen como fundamento la capacidad del ser humano para autodeterminarse, facultad de la que se entiende desprovistos a los menores de edad, debido principalmente a dos causas: la percepción del niño como ser absolutamente vulnerable y dependiente y la pertenencia del niño a la familia, vinculada con el ejercicio de la patria potestad. ${ }^{36}$

Parece entonces que no resulta tan obvio que la titularidad, tal cual aparecen los diferentes derechos en la Constitución, es aplicable a los niños y adolescentes, y pese a que muchos de estos derechos se encuentran previstos en la Convención y otros instrumentos internacionales, existe aún cierta resistencia a su reconocimiento durante la minoría de edad. La misma idea de reconocer interés jurídico a un niño para promover un juicio de amparo en contra de una norma inconstitucional por ser violatoria de este tipo de derechos parecería dudosa para muchos juristas.

En esta misma línea, el derecho a expresar su opinión e intervenir en los asuntos que le afectan directamente, se vuelve especialmente relevante pues, a diferencia de lo que sucede durante la mayoría de edad en don-

35 Incluso algunas autores sostienen que la libertad de religión en los mayores de edad supone el derecho a educar a los hijos en las propias creencias, imponiendo una obligación al Estado de no intervenir en esta libertad. Esta interpretación refleja, además de que no resulta tan clara la titularidad de esta libertad durante la infancia, la idea de los niños como parte del ámbito de inmunidad de los adultos frente al Estado. La misma Convención reconoce en el artículo 14-2: "Los Estados partes respetarán los derechos y deberes de los padres y, en su caso, de los representantes legales, de guiar al niño en el ejercicio de su derecho de modo conforme a la evolución de sus facultades".

36 González Contró, Mónica, "Comentario del Instituto de Investigaciones Jurídicas de la Universidad Nacional Autónoma de México. Responsabilidad de los menores de dieciséis años, conforme a las disposiciones legales sobre menores y responsabilidad de los mayores de 16 años, conforme al Código Penal del Estado de Guanajuato", Inconstitucionalidad de los ordenamientos que establecen una edad mínima penal distinta a la señalada en el artículo 18 de la Constitución federal, México, Decisiones relevantes de la Suprema Corte de Justicia de la Nación, 2007, p. 76. 
de se interpreta que la autodeterminación es la regla, en la minoría de edad se entiende, en el mejor de los casos, como la excepción..$^{37}$ Este derecho, reconocido en el artículo 12 de la Convención, establece la obligación del Estado de garantizar el derecho a expresar su opinión en los asuntos que afectan al niño que "esté en condiciones de formarse un juicio propio", "teniéndose debidamente en cuenta las opiniones del niño, en función de la edad y madurez del niño". Para cumplir lo anterior, debe dársele la oportunidad de ser escuchado, ya sea directamente o por medio de un representante $u$ órgano apropiado en los procedimientos judiciales o administrativos. Para Freeman, es la disposición más innovadora y significativa del convenio y deriva de la filosofía liberacionista de los años setentas. ${ }^{38}$

Resulta así que, al establecer la forma en que la autodeterminación genérica debe ser entendida en los niños, el principio es de fundamental importancia, pues permite además acotar el autoritarismo que en muchas de las decisiones se impone a los niños y adolescentes al permitirles expresar su opinión. Este derecho se encuentra también vinculado con la idea de dignidad humana y el principio de autonomía progresiva.

El derecho a la protección especial en contra del maltrato, abandono y abuso deja ver la otra cara de la moneda respecto de los derechos de los niños, pues aunque se ha hecho énfasis en que se ha exagerado la idea de dependencia, es una realidad que la infancia constituye una etapa de vulnerabilidad que requiere de protección especial en algunos supuestos. Esto supone un derecho de tutela explícito contra las prácticas intolerables que afectan a la infancia como serían: el abuso sexual, la pornografía, la explotación sexual, el secuestro, la venta, la realización de trabajos riesgosos, etcétera, y la obligación del Estado en la adopción de medidas

37 Un ejemplo de esta postura sostenida por Alf Ross es rebatida por Liborio Hierro: "En consecuencia Ross parece suponer que los niños están sometidos — respecto a la potestad de sus padres - a una norma general prohibitiva. Sólo bajo esta suposición cabe, en efecto, afirmar que lo que no se les ha permitido les está prohibido. Esta suposición de una norma general prohibitiva ha estado vigente en todos los modelos de educación autoritaria", Hierro, Liborio L., "Conceptos jurídicos fundamentales (I) De las modalidades deónticas a los conceptos de derecho y deber", Revista Jurídica, Universidad Autónoma de Madrid, núm. 3, 2000, p. 155.

38 Freeman, Michael D. A., "The Moral Status of Children. Essays on the Rights of the Child", Kluwer Law International and Martinus Nijhoff, The Netherlands, Dordrecht, 1997, p. 153. 
de todo tipo para su prevención y sanción. Esta clase de derechos implica también una prohibición de ciertos estilos educativos que actualmente pueden ser considerados como maltrato y que entrañan básicamente la no satisfacción de cualquiera de las necesidades.

El derecho explícito a la protección en contra de estos actos constituye una directriz en la actuación del Estado respecto de los niños y establece la responsabilidad en todas las esferas de gobierno de orientar las instituciones (leyes, políticas, etcétera) para evitar y remediar cualquier situación de esta naturaleza. Es importante hacer mención que el texto constitucional debe establecer que cualquier persona tiene el deber de denunciar una circunstancia de este tipo, de forma que el Estado pueda intervenir inmediatamente. Desgraciadamente la realidad muestra cada vez de forma más cruda la necesidad de reconocer, proteger y garantizar este derecho:

Los adultos debemos responder a estas necesidades de los menores, porque, ellos no tienen la misma capacidad de autoprotección que los adultos: son más vulnerables, no pueden decidir sobre su vida de la misma forma, no se saben defender bien de los peligros y pueden sufrir efectos más irreversibles. Estos hechos, entre otros, hacen necesaria la función protectora de los adultos. ${ }^{39}$

\section{CONCLUSIONES}

Como se ha intentado demostrar a lo largo de este trabajo, el reconocimiento de la titularidad de derechos a los niños, niñas y adolescentes no ha sido un proceso sencillo. Por esta razón, no resulta extraño que el actual texto del artículo 4o. constitucional se haga eco de las viejas ideas y contenga contradicciones con el resto de la norma fundamental respecto de los derechos de la persona durante los primeros años de su vida. Evidentemente que la reforma de 2000 significó un enorme avance, pero se requiere una nueva revisión a la luz de los criterios desarrollados en los últimos años que garantice de manera efectiva la titularidad y el cumplimiento de los derechos de niños, niñas y adolescentes.

39 López, Félix, Necesidades de la infancia y protección infantil, Madrid, Ministerio de Asuntos Sociales, 1995, p. 53. 
Dos son los principales obstáculos para lograr este cambio necesario: la temporalidad de la característica que ha excluido a niños y adolescentes de la titularidad de derechos y la pertenencia del niño a la familia en relación con la percepción sobre los derechos de la patria potestad. La primera consideración hace aparecer como irrelevante una verdadera garantía de los derechos, pues la infancia finalmente será dejada atrás y, cuando esto suceda, el individuo tendrá plena capacidad de goce y de ejercicio de los derechos constitucionales. El segundo problema deviene de una larga tradición liberal en la que el niño constituye casi una propiedad de los padres, por lo que resulta amenazante la injerencia pública. Ambas dificultades deben ser superadas para lograr la vigencia de un Estado constitucional de derecho, particularmente en nuestro país, pues desde esta óptica resulta inaceptable la negativa de la titularidad de derechos a cualquier individuo con base en cualquier consideración que no sea la del respeto a su dignidad humana.

La creación de un artículo destinado exclusivamente al reconocimiento de los derechos de los niños, niñas y adolescentes es, sin embargo, solo el primer paso en una larga transformación que deberá llevar a la mención expresa de las particularidades de cada uno de los derechos durante la minoría de edad y, sobre todo, al reconocimiento de los niños y adolescentes como ciudadanos en desarrollo, con facultades para irse integrando poco a poco a la vida política del Estado democrático. Para ello hace falta un cambio cultural y social respecto de la percepción de la infancia y adolescencia, transformación que parece ha empezado a gestarse lentamente a través de mecanismos de participación cada vez más tendentes a reconocer la importancia de los derechos humanos y su efectiva vigencia.

\section{BIBLIOGRAFÍA}

BÁRCENA, Andrea, Textos de derechos humanos sobre la niñez, México, Comisión Nacional de Derechos Humanos, 1992.

DELVAL, Juan, "Algunas reflexiones sobre los derechos de los niños", Infancia y sociedad, Madrid, 27-28, Ministerio de Asuntos Sociales, Dirección General del Menor y la Familia, 1994. 
FrEEMAN, Michael D. A., "The Moral Status of Children. Essays on the Rights of the Child", Kluwer Law International and Martinus Nijhoff, The Netherlands, Dordrecht, 1997.

Derechos del Pueblo Mexicano. Reformas constitucionales durante la LVII Legislatura (1997-2000), México, Cámara de Diputados, Senado de la Republica, Poder Judicial de la Federación, TE, IFE, Porrúa, 2006, t. XIII.

GARCÍA MÉNDEZ, Emilio, Infancia-Adolescencia. De los derechos y de la justicia, México, Distribuciones Fontamara, 2001.

GONZÁlEZ CONTRÓ, Mónica, "Los derechos fundamentales del niño en el contexto de la familia", en ÁlVAREZ DE LARA, Rosa Ma. (coord.), $P a$ norama internacional de derecho de familia. Culturas y sistemas jurídicos comparados, México, UNAM, Instituto de Investigaciones Jurídicas, 2006.

, "Comentario del Instituto de Investigaciones Jurídicas de la Universidad Nacional Autónoma de México. Responsabilidad de los menores de dieciséis años, conforme a las disposiciones legales sobre menores y responsabilidad de los mayores de 16 años, conforme al Código Penal del Estado de Guanajuato", Inconstitucionalidad de los ordenamientos que establecen una edad mínima penal distinta a la señalada en el artículo 18 de la Constitución federal, México, Decisiones relevantes de la Suprema Corte de Justicia de la Nación, SCJN, 2007.

HIERRO, Liborio L., "Conceptos jurídicos fundamentales (I) De las modalidades deónticas a los conceptos de derecho y deber", Revista Jurídica, Universidad Autónoma de Madrid, núm. 3, 2000.

—_ "La intimidad de los niños: un test para el derecho a la intimidad", en SAuCA, José Ma. (ed.), Problemas actuales de los derechos fundamentales, Madrid, Universidad Carlos III de Madrid, Boletín Oficial del Estado, 1994.

,"Los derechos de la infancia, razones para una ley", Estudios Jurídicos en homenaje al profesor Aurelio Menéndez, Madrid, Cívitas, vol. IV, 1996.

_ _ "Tienen los niños derechos? Comentario a la Convención sobre los Derechos del Niño", Revista de Educación, Madrid, núm. 294, enero-abril de 1991.

LÓPEZ, Félix, Necesidades de la infancia y protección infantil, Madrid, Ministerio de Asuntos Sociales, 1995. 
MACCORMICK, Neil, "Los derechos de los niños: una prueba para las teorías del derecho", Derecho legal y socialdemocracia, Madrid, Tecnos, 1990.

MADRAZO, Jorge, “Artículo 4o.”, Derechos del Pueblo Mexicano, México, Cámara de Diputados, Senado de la República, Poder Judicial de la Federación, TE, IFE, Porrúa, 2006.

MORENO, Amparo y BARRIO, Cristina del, La experiencia adolescente. A la búsqueda de un lugar en el mundo, Buenos Aires, Sigue, 2000.

OCHAÍTA, Esperanza y ESPINOSA, María Ángeles, "Dificultades en el desarrollo de origen social: definición, incidencia, tipos y consecuencias del maltrato infantil", en GARCÍA SÁNCHEZ, J. N. (comp.), Intervención psicopedagógica en trastornos del desarrollo, Madrid, Pirámide, 1999.

_- Hacia una teoría de las necesidades infantiles y adolescentes. Necesidades y derechos en el marco de la Convención de Naciones Unidas sobre Derechos del Niño, McGrawHill-UNICEF, 2004.

PERrot, Michelle, "Figuras y funciones", en ArIÈS, Phillipe y DUBY, Georges (dirs.), Historia de la vida privada, Madrid, Taurus, 1993, t. 4.

PRIETO SANCHÍS, Luis, "Neoconstitucionalismo y ponderación judicial", en CARBonell, Miguel (coord.), Neoconstitucionalismo(s), Madrid, Trotta, 2003.

SALAZAR UGARTE, Pedro, La democracia constitucional. Una radiografía teórica, México, Fondo de Cultura Econónica-UNAM, Instituto de Investigaciones Jurídicas, 2006. 